\title{
Capsid Assembly is Regulated by Amino Acid Residues Asparagine 47 and 48 in The VP2 Protein of Porcine Parvovirus
}

\section{Jucai Wang}

Henan Academy of Agricultural Sciences

\section{Yunchao Liu}

Henan Academy of Agricultural Sciences

\section{Yumei Chen}

Zhengzhou University

\section{Teng Zhang}

Henan Academy of Agricultural Sciences

Aiping Wang

Zhengzhou University

\section{Qiang Wei}

Henan Academy of Agricultural Sciences

\section{Dongmin Liu}

Henan Zhongze Biological Engineering Co., Ltd

\section{Fangyu Wang}

Henan Academy of Agricultural Sciences

Gaiping Zhang ( $D$ zhanggaiping2003@163.com )

Henan Agricultural University

\section{Research}

Keywords: Porcine parvovirus, capsid assembly, 47Asn, 48Asn, VP2 macromolecular polymers

Posted Date: September 15th, 2020

DOI: https://doi.org/10.21203/rs.3.rs-72147/v1

License: (c) (i) This work is licensed under a Creative Commons Attribution 4.0 International License. Read Full License

Version of Record: A version of this preprint was published at Veterinary Microbiology on February 1st, 2021. See the published version at https://doi.org/10.1016/j.vetmic.2020.108974. 


\section{Abstract}

Background: Porcine parvovirus (PPV) is a major cause of reproductive failure in swine, and has caused huge losses throughout the world. Viral protein 2 (VP2) of PPV is a major structural protein that can selfassemble into virus-like particles (VLP) with hemagglutination (HA) activity. In order to identify the essential residues involved in the mechanism of capsid assembly and to further understand the function of HA, we analyzed a series of deletion mutants and site-directed mutations within the N-terminal of VP2 in the Escherichia coli (E. coli) system.

Results: Our results showed that deletion of first 47 amino acids from the N-terminal of VP2 protein did not affect capsid assembly, and further truncation to residue 48 Asparagine (Asn, $\mathrm{N}$ ) caused detrimental effects. Site-directed mutagenesis experiments demonstrated that residue 47Asn reduced the assembly efficiency of PPV VLP, while residue 48Asn destroyed the stability, hemagglutination, and self-assembly characteristics of the PPV VP2 protein. These findings indicated that the residues 47Asn and 48Asn are important amino acid sites to capsid assembly and HA activity. Results from Native PAGE inferred that macromolecular polymers were critical intermediates of the VP2 protein during the capsid assembly process. Site-directed mutation at 48Asn did not affect the association of monomers to form into oligomers, but destroyed the ability of oligomers to assemble into macromolecular particles, influencing both capsid assembly and HA activity.

Conclusions: These results demonstrated that PPV capsid assembly is a complex process that is regulated by amino acids 47Asn and 48Asn, which are located at the N-terminal of VP2 and closely related to the association of macromolecular particles. Our findings provide valuable information on the mechanisms of PPV capsid assembly and the possibility of chimeric VLP vaccine development by replacing as much as 47 amino acids at the $\mathrm{N}$-terminal of VP2 protein.

\section{Background}

Porcine parvovirus (PPV), a member of the genus Parvovirus, family Parvoviridae, is a common pathogen associated with reproductive failure in swine [1, 2]. It is a single-stranded DNA virus, which packages its DNA into a $T=1$ nonenveloped, icosahedral capsid that is $26 \mathrm{~nm}$ in diameter [3]. The capsid of PPV is formed by 60 copies of a mixture of viral proteins (VP) VP1, VP2, and VP3 [4]. VP1 and VP2 are generated through alternative splicing, and they share a common C-terminal region, but VP1 contains unique 150 amino acid residues at the N-terminal extension [5]. The major capsid protein, VP2, is able to selfassemble into empty capsids alone, known as virus-like particles (VLP), which is a major antigen to induce neutralizing antibodies [6]. The VP3 protein is generated from the cleavage of VP2 at approximately 25 amino acids from the $\mathrm{N}$-terminal [7].

The structure of PPV capsids has been solved by using X-ray crystallography with data to $3.5 \mathrm{~A}$ [8]. Similar to other parvoviruses, PPV capsid subunits consists of eight anti-parallel, $\beta$-strand motifs and four large loops, which make up most of the exposed surface of the capsid $[9,10]$. Protruding "spikes" 
surrounding the icosahedral three-fold axes of parvovirus are related to host-receptor recognition, cell tropism, hemagglutination (HA) activity, and antigenicity [11, 12]. Amino acid residues 93,103 , or 323 , located in structural regions near the three-fold "spike" of the capsid, are responsible for the host range differences between canine parvoviruses and feline panleukopenia viruses [13]. Amino acids that determine tissue tropism were found to cluster on the viral surface, such as amino acid residues 317 or 321 of VP2 in minute virus of mice (MVM), and residues 381, 386, and 436 in PPV [8, 14]. Apart from its important roles in determining tropism and host range, the capsid also contains major antigenic sites, hemagglutination sites, lack infectious virus and are inherently safer comparable to those of the native virion $[15,16]$. These beneficial characteristics make PPV VLP as the best vaccine candidate, which expressed in many different systems [17-19]. Recent years, VLP attracts broad scientific interest due to their properties as versatile scaffold in nanotechnology, such as potential therapeutic agents, targeted drug delivery, novel vaccines and so on [20-23]. PPV VLP, excepting originated advantages from their particle integrity, its simple structure makes it as an ideal platform in biomedicine to study the mechanisms of capsid assembly and virus infection, as well as the development of new vaccines [24, 25].

Virus self-assembly and virion morphogenesis are regulated by different types of protein subunits, such as monomers, dimers, trimers, pentamers, or hexamers. Both the assembly and stability are protected from the formation of multiple non-covalent interactions between protein subunits [26, 27]. Trimers, as the intermediates, may exert morphogenetic control on the icosahedral parvovirus capsids during the assembly of MVM [28, 29]. In polyomavirus, pentamers of VP1, the major capsid protein, associated with VP2 and VP3 complexes within the cytoplasm were shown to be responsible for cooperative nuclear translocation [30]. Key amino acid residues or most non-covalent interactions between protein subunits, such as hydrophobic, hydrogen bonds or salt bridges, may be critical for the assembly and stability of virions [31,32]. As intermediates and intermolecular interactions play an important role in the function of virus capsid, it is very meaningful to further study of this work. Knowledge of capsid assembly, stability, and dynamics of PPV virions is essential to understand the virus life cycle and promote the development of antiviral vaccines and antiviral agents based on inhibiting the assembly and uncoating process.

In order to identify the functional domains of the VP2 protein involved in capsid assembly and HA activity, we constructed ten deletion mutants and three site-directed mutants within the N-terminal domain of VP2 in the Escherichia coli (E. coli) system. Our results demonstrated that truncation of the Nterminal of VP2 at amino acid residue 47 did not affected VLP assembly and HA activity. Further truncation to residue 48 Asparagine (Asn, N) caused detrimental effects. Site-directed mutagenesis demonstrated that residues 47Asn-48Asn were the key amino acid sites controlling VLP assembly and HA activity. Our results also indicated that mutation of 48Asn did not affect the formation of monomers into oligomers, but prevented the assembly of oligomers into macromolecular particles, which eventually destroyed VLP formation.

\section{Results}




\section{Expression of mutant VP2 proteins in E. coli cells}

In order to screen the residues involved in HA and assembly features of PPV capsids, we designed and expressed a series of deletion mutants and site-directed mutants of the VP2 protein in E. coli (Fig. 1). First, three $\mathrm{N}$-terminal deletion mutants, with 30, 50, and 100 amino acid residues of the VP2 protein removed (namely NT- $\Delta 30 \mathrm{aa}, \mathrm{NT}-\Delta 50 \mathrm{aa}, \mathrm{NT}-\Delta 100 \mathrm{aa}$, respectively), were constructed. Only the NT- $\Delta 30 \mathrm{aa}$ protein was successfully expressed in soluble form in E. coli and exhibited HA activity, reaching $2^{16}$ in vitro. However, the NT- $\Delta 50$ aa and NT- $\Delta 100$ aa mutant proteins were insoluble, and none of them could agglutinate guinea pig erythrocytes (Table 2 and Fig. 2). Subsequently, the NT- $\Delta 35 a a, N T-\Delta 40 a a, N T-$ $\Delta 45 \mathrm{aa}, \mathrm{NT}-\Delta 46 \mathrm{aa}, \mathrm{NT}-\Delta 47 \mathrm{aa}, \mathrm{NT}-\Delta 48 \mathrm{aa}$, and NT- $\Delta 49$ aa mutants were expressed as soluble forms in the supernatant of $E$. coli cells (Fig. 2). Among these soluble mutant VP2 proteins, NT- $\Delta 30$ aa, NT- $\Delta 35$ aa, NT$\Delta 40$ aa, NT- $\Delta 45$ aa, NT- $\Delta 46$ aa, and NT- $\Delta 47$ aa exhibited HA activity, with the HA titers reaching $2^{16}, 2^{16}$, $2^{16}, 2^{15}, 2^{16}$, and $2^{10}$, respectively. Both NT- $\Delta 48$ aa and NT- $\Delta 49$ aa did not have HA activity (Table 2 ), indicating that the first 47 amino acid residues were responsible for the HA activity of PPV capsids. Interestingly, both 47 and 48 amino acid residues were asparagine. Next, we then designed and constructed another three mutants, N47K, N48K, and N47KN48K, using site-directed mutagenesis, where we replaced 47Asn and/or 48Asn amino acid with lysine (Lys, K) in the VP2 protein (Fig. 1). As shown in Fig. 3a, three mutants were expressed as soluble forms. The results from the HA test showed that only the N47K mutant exhibited HA activity, with the titers of $2^{14}$, and the N48K and N47KN48K mutants showed no HA activity (Fig. 3b). These results further indicated that the 47Asn and 48Asn residues are crucial amino acids that play an important role in the structure and function of PPV capsids.

\section{Purification of mutant VP2 proteins}

Five mutant VP2 proteins-NT- $\Delta 30 \mathrm{aa}, \mathrm{NT}-\Delta 47 \mathrm{aa}, \mathrm{NT}-\Delta 48 \mathrm{aa}, \mathrm{N} 47 \mathrm{~K}$, and N48K-and the native VP2 protein were chosen for further analyses. Fractions containing native VP2 or mutant VP2 proteins were eluted with $50 \mathrm{mM}$ Tris containing $150 \mathrm{mM} \mathrm{NaCl}$ and $150 \mathrm{mM}$ imidazole through Ni-NTA affinity chromatography. The eluates were then monitored continuously by UV-absorption at $280 \mathrm{~nm}$, and the active fractions were recovered through size-exclusion high-performance liquid chromatography (SEHPLC). Our SDS-PAGE analysis results showed that the purity of these proteins was over 90\% (Figs. 4a4f). As shown in the chromatogram, mutant VP2 and native VP2 protein had only one main peak, whereas the N47K protein had two main peaks (Fig. 4). As compared to the native VP2 protein, the main peak of the VP2 deletion mutants was observed at about 8.5 minutes, except for NT- $\Delta 48$ aa, which was observed at 7.3 minutes (Fig. $4 \mathrm{~g}$ and Table 3). As for the two site-directed mutants, the main peak of N48K, which appeared at around 7.5 minutes, was earlier than that of N47K and native VP2 (Fig. 3h and Table 3). Moreover, the main peak of NT- $\Delta 48$ aa was in accord with N48K, which was almost at 7.3 minutes -1 minute earlier than that of the native VP2 protein (Fig. 4i and Table 3). Detailed information regarding the elution times of the VP2 mutant proteins is summarized in Table 3.

\section{Identification of key amino acid residues in assembly of PPV capsids}


Self-assembly properties of mutant VP2 proteins in vitro were confirmed by transmission electron microscopy (TEM) and dynamic light scattering assay (DLS). Results from TEM showed that regular VLP were observed in the native VP2 protein and NT- $\Delta 30 \mathrm{aa}, \mathrm{NT}-\Delta 47 \mathrm{aa}$, and N47K, but not in NT- $\Delta 48 \mathrm{aa}$ and N48K (Fig. 5). NT- $\Delta 48$ aa and N48K particles showed some amount of aggregation or multimeric structure with completely irregular particles, which differed morphologically from regular VLP (Figs. $5 d$ and $5 f$ ). Consistently, results from DLS demonstrated that the native VP2 protein, NT- $\Delta 30 a a, N T-\Delta 47 a a$, and N47K self-assembled into particles in solution, with an average diameter of $25 \mathrm{~nm}$, but NT- $\Delta 48 \mathrm{aa}$ and N48K existed as non-uniform particle sizes, as indicated in Fig. 6 and Table 3. Additionally, we further investigated whether the $\mathrm{N}$-terminal deletion and site-directed mutant proteins retained the ability to react with the conformational monoclonal antibody $10 \mathrm{~A}$, which only recognizes assembled capsids. As shown in Fig. 7, NT- $\Delta 30$ aa, NT- $\Delta 47 \mathrm{aa}$, N47K (peak 1), and full-length VP2 reacted with the conformational monoclonal antibody $10 \mathrm{~A} 9$ with titers above 1:640,000, but N47K (peak 2), NT- $\Delta 48 \mathrm{aa}$, and N48K did not. These results indicated that 47Asn and 48Asn are key amino acid residues of the VP2 protein, which have a significance effect on capsid assembly.

\section{Analysis of mutant VP2 proteins by sucrose gradient sedimentation}

Sucrose gradient sedimentation was conducted to analyze the stability and aggregation states of mutant VP2 proteins. As shown in Fig. 8a, the native VP2 protein was detected mainly in fraction 14, with one peak in the $45 \%$ sucrose gradient. The NT- $\triangle 30$ aa mutant behaved similarly to the native VP2 protein, and particles were observed primarily in the $45 \%$ sucrose gradient. This suggested that, similar to the fulllength VP2 protein, the NT- $\Delta 30$ aa protein was assembled into VLP with high stability (Fig. 8b). As compared with the full-length VP2 protein, numerous unassembled VP2 proteins in the NT- $\Delta 47 \mathrm{aa}$, NT$\triangle 48 \mathrm{aa}, \mathrm{N} 47 \mathrm{~K}$, and N48K mutants accumulated and migrated as different protein subunits within the 5$45 \%$ sucrose gradient (Figs. $8 \mathrm{c}-8 \mathrm{f}$ ). These results implied that the 47 Asn and 48 Asn residues affected the stability of the VLP structure, resulting in a large amount of intermediate aggregation, which reduced assembly efficiency and VLP formation.

Native PAGE was employed to estimate and compare unassembled subunits or intermediates in native VP2 and mutant N48K protein during the VLP formation process. As shown in Fig. 9a, there were five intermediates (a-e) in the unpurified VP2 capsids (lane 1). The intermediate a was at a position of 1236 $\mathrm{kDa}, \boldsymbol{b}$ at $1048 \mathrm{kDa}, \boldsymbol{c}$ at about $720 \mathrm{kDa}$ (below), $\mathbf{d}$ at $480 \mathrm{kDa}$ (below), and e at $146 \mathrm{kDa}$. Small oligomers, such as intermediates $\mathbf{d}$ and $\mathbf{e}$, were not detected in any sucrose layer. VP2 protein commonly exists as macromolecular particles, such as intermediate $\mathbf{a}$ and $\mathbf{b}$, in the purified assembled VLP solution (lane 14 in Fig. 9a). When amino acid residue 48 was mutated from an Asn to Lys, numerous unassembled proteins were detected in the N48K mutant, as indicated in Fig. $9 \mathrm{~b}$. Three new unassembled subunits in the N48K mutant, $\mathbf{f}$ at $720 \mathrm{kDa}, \mathbf{h} 480 \mathrm{kDa}$ (upper), and $\mathbf{i}$ at $242 \mathrm{kDa}$, were observed, excepting two unassembled subunits $\mathbf{g}$ at about $720 \mathrm{kDa}$ (below) and $\mathbf{j}$ at about $146 \mathrm{KDa}$, located in the same position with $\mathbf{c}$ and $\mathbf{e}$ intermediates in VP2 protein (Lane 1 in Fig. 9). Importantly, these five unassembled subunits of N48K accumulated and migrated as major proteins in different sucrose layers (Fig. 9b). Notably, macromolecular polymers $\mathbf{a}$ and $\mathbf{b}$ were not detected in the N48K mutant (lane 1 and 14 in Fig. 9). The 
results from liquid chromatography-tandem mass spectrometry (LC-MSMS) analysis showed that these intermediates $(\mathbf{a}-\mathbf{j})$ were all VP2 or mutant VP2 proteins, which represented different unassembled VP2 subunits during the VLP formation process (Fig. S1). Based on the results described above, we preliminary inferred that macromolecular polymers $\mathbf{a}$ (at $1236 \mathrm{kDa}$ ) and $\mathbf{b}$ (at $1048 \mathrm{kDa}$ ) may be critical intermediates of the VP2 protein, and site-directed mutation at the 48Asn amino acid impeded aggregation of the VP2 macromolecular particles, which is an important factor that rendered the VP2 protein defective in VLP formation during the capsid assembly process.

\section{Discussion}

PPV VP2 has both antigenicity and immunogenicity and can self-assemble into VLP in vitro. These VLP do not contain genetic material as found in the native virion, which makes these VLP suitable for studying viral packing and assembly, vaccine design, and biological nanomaterials. In our previous study, we investigated the HA and self-assembly characteristics of full-length VP2 protein capsids in vitro, and VP2 VLP showed a prominent advantage in immunogenicity and immunoprotection $[19,33]$. However, the mechanisms of self-assembly of PPV capsids is still unclear. In this study, we constructed a series of mutants with N-terminal deletions and site-directed mutations in the full-length VP2 protein in order to identify regions that regulated VLP formation and HA activity. Our results demonstrated that PPV capsid assembly is a complex process that is regulated by amino acids 47Asn and 48Asn, which are located at the N-terminal of VP2 and closely related to the association of macromolecular particles.

Structural proteins, as well as their critical residues, play an irreplaceable role in protein self-association and capsid assembly. Deletion of five C-terminal residues or merely glutamic acid 257 of VP3 in the infectious bursal disease virus was found to promote capsid assembly [34]. Deletion of 27 residues or less from the N-terminal of the VP2 protein in porcine circovirus type 2 resulted in a similar icosahedral shape and immunogenicity as compared with the full-length VLP [35]. Additionally, deleting up to 125 amino acid residues from the $\mathrm{N}$-terminal region of the capsid protein and truncating the $\mathrm{C}$-terminal of the capsid region to 601 amino acid residues in hepatitis $\mathrm{E}$ virus was conducive for the self-assembly of viral particles [36]. In order to locate the key domains that may impact HA activity and assembly features of PPV capsids, ten mutant VP2 proteins were expressed in an E. coli system. As shown in Fig. 2, mutant proteins were expressed in the supernatant of $E$. coli cells, except NT- $\Delta 100 \mathrm{aa}$ and NT- $\Delta 50$ aa proteins, which aggregated as inclusion bodies. However, among these soluble mutant VP2 proteins, six mutants, NT- $\Delta 47 a a, N T-\Delta 46 a a, N T-\Delta 45 a a, N T-\Delta 40 a a, N T-\Delta 35 a a$, and NT- $\Delta 30 a a$, had HA activity; mutants NT$\Delta 49$ aa and NT- $\Delta 48$ aa did not have HA activity (Table 2). To investigate the self-assembly and biological functions of the N-terminal deletion mutants, three mutants, NT- $\Delta 30 \mathrm{aa}$, NT- $\Delta 47 \mathrm{aa}$, and NT- $\Delta 48 \mathrm{aa}$, were chosen for further study. Results from TEM and DLS analysis confirmed that typical VLP formed in the NT- $\Delta 30$ aa and NT- $\Delta 47$ aa mutants, with a particle size about $25 \mathrm{~nm}$, but not in NT- $\Delta 48$ aa (Figs. $5-6$ and Table 3). Results from the indirect enzyme-linked immunosorbent assay (ELISA) showed that NT- $\Delta 30 \mathrm{aa}$, NT- $\triangle 47 \mathrm{aa}$, and VP2 were recognized by the conformational monoclonal antibody $10 \mathrm{~A} 9$, with titers above $1: 640,000$. However, NT- $\Delta 48$ aa was not recognized by the antibody $10 \mathrm{~A} 9$, which only recognizes assembled VP2 capsids, implying NT- $\Delta 48$ aa did not properly assemble. The results described above 
suggested that when the 48Asn amino acid was removed from the VP2 protein, the protein lost the ability to hemagglutinate guinea pig erythrocytes and was unable to self-assemble into VLP, indicating that 47Asn and 48Asn are the critical residues involved in the function of HA activity and capsid assembly during the VLP formation process.

At physiological conditions, homogeneous VLP assembled, while at acidic or basic pHs, with low ionic strength, the major assemblies were small intermediates [37]. It has been reported that residues involved in hydrogen bonds, hydrophobic interactions, and salt bridges or heterologous peptide insertions may have an effect on the stability and assembly of viral proteins [25,31,38].Site-directed mutations in capsid protein has proved to modify the properties or function of virus capsids [39-41]. In this study, deleting the first 47 amino acid residues within the N-terminal region of the VP2 capsid protein had no significant effect on HA and self-assembly characteristics of PPV capsids. However, deletion of amino acid 48 resulted in loss of HA activity and VLP formation. Considering that amino acids 47 and 48 are both asparagine, three mutants (N47K, N48K, and N47KN48K) were designed and constructed by replacing 47Asn and/or 48Asn amino acid with lysine in the VP2 protein. As shown in Fig. 3a, the mutants were expressed as soluble proteins in E. coli. Results from the HA assay indicated that only the N47K mutant exhibited HA activity, with $2^{14}$ titers (Fig. $3 b$ ). The ability of purified N47K and N48K to self-assemble into VLP in vitro was assessed by TEM, DLS, and ELISA assays. Results from TEM and DLS revealed that VLP were observed in the N47K mutant, but not in the N48K mutant (Figs. 5-6). As shown in Fig. 7, the N48K mutant was not recognized by the conformational monoclonal antibody $10 \mathrm{~A} 9$, which only reacts with assembled capsids. Site-directed mutations or deletion of amino acids within the N-terminal of the VP2 protein changed the morphology and function of PPV VLP. Sucrose gradient sedimentation was employed to analyze the effects of mutations on the formation and stability of PPV capsids during the VLP formation process. Notably, results from sucrose gradient sedimentation showed that the mutant VP2 proteins were distributed within the $5-45 \%$ sucrose, implying that there were unassembled protein subunits that accumulated, as seen in the NT- $\Delta 47 \mathrm{aa}, \mathrm{NT}-\Delta 48 \mathrm{aa}, \mathrm{N} 47 \mathrm{~K}$ and N48K mutants, but not the NT$\triangle 30$ aa mutant and native VP2 protein (Fig. 8). This suggested that 47Asn-48Asn residues are critical amino acids involved in the self-assembly process and stability of PPV VLP. Residue 47Asn reduced the assembly efficiency of PPV VLP, while residue 48Asn destroyed the stability, hemagglutination, and selfassembly characteristics of the PPV VP2 protein. We preferred to deem that because the stability structure of PPV VLP was destroyed, and hence made VP2 capsids lost its HA activity. However, further research needs to be performed in order to better understand the underlying mechanism.

Virus capsids are assembled from stable forms or assembly intermediates. These structures may be soluble monomers or small oligomers (e.g., dimers, trimers, pentamers, hexamers), and can be detected in the dynamic balance of assembled-unassembled capsids, depending on the virus and conditions [26]. The trimer was confirmed as the transient intermediate existing during the assembly of MVM VLP, and capsid formation was dependent upon stronger intertrimer interactions that were equally spaced in an equatorial belt surrounding each trimer $[28,29]$. Present studies have shown that 48 Asn residue in the VP2 protein directly impacted the structure or function of viral particles, and deletion or mutation at this 
site rendered the VP2 protein defective in assembling capsids. As shown in Fig. 8f, results from sucrose gradient sedimentation showed that a number of unassembled subunits existed in the N48K mutant, which might represent different oligomers or polymers formed by the VP2 protein. Native PAGE was employed to evaluate the native conditions of these unassembled subunits in the N48K mutant during the VLP formation process. Comparing the N48K mutant with the native VP2 protein, intermediates a (at about $1236 \mathrm{kDa}$ ) and $\mathbf{b}$ (at about $1048 \mathrm{kDa}$ ) were detected as major protein subunits in VP2 capsids, while intermediates $\mathbf{f}$ (at $720 \mathrm{kDa}$ ), $\mathbf{g}$ (720 kDa below), $\mathbf{h}$ (at $480 \mathrm{kDa}$ upper), $\mathbf{i}$ (at $242 \mathrm{kDa}$ ), and $\mathbf{j}$ (at $146 \mathrm{kDa}$ ) aggregated in the N48K mutant (Fig. 9). These intermediates in the N48K mutant appeared as small oligomers, such as dimers ( $j$ at $146 \mathrm{kDa}$ ), trimers (i at $242 \mathrm{kDa}$ ), pentamers ( $\mathrm{h}$ at $480 \mathrm{kDa}$ upper), as well as a complex ( $\mathbf{f}$ at $720 \mathrm{kDa}$ and $\mathbf{g}$ at $720 \mathrm{kDa}$ below), and accumulated in large amounts, which eventually had a significant negative affect on the formation of VLP. Importantly, the intermediates a and

b were not observed in the N48K mutant, which were two important intermediates of VP2 protein during the VLP assembly process. We preliminarily deduced that the macromolecular particles, intermediate a located at about $1236 \mathrm{kDa}$ and intermediate $\boldsymbol{b}$ at about $1048 \mathrm{kDa}$, may be formed by pentamers or trimers. Although the mechanisms of PPV capsid assembly remains unclear, our data suggested that sitedirected mutagenesis at 48Asn did not affect the association of monomers to form into oligomers, but destroyed the ability of oligomers to assemble into macromolecular particles. This resulted in adverse effects on VLP formation and HA activity.

\section{Conclusions}

In summary, we investigated the key amino acid sites within the N-terminal region of the VP2 protein, which may control and affect VLP formation and HA activity of PPV capsids. Deletion of the first 47 amino acids within the N-terminal had no effect on VLP assembly, whereas deletion of the first 48 amino acids resulted in loss of VLP formation. Site-directed mutagenesis experiments indicated that residue 47Asn reduced the assembly efficiency of PPV VLP, while residue 48Asn had a detrimental effect on the stability and function of PPV capsids. Further research revealed that mutation at 48Asn impeded the ability of oligomers to assemble into macromolecular particles, which eventually had a negative effect on VLP formation. These findings provided new insights into understanding the mechanisms of PPV capsid assembly and valuable information regarding designing chimeric VLP vaccines by replacing the first 47 amino acid residues at the N-terminal of the VP2 protein.

\section{Methods}

\section{Construction of capsid VP2 mutants}

Ten mutants with amino acids deleted from the N-terminal region of the VP2 capsid protein and three site-directed mutations in VP2 were constructed using the $E$. coli expression system (Fig. 1). The VP2 gene was truncated at the N-terminal by inserting PCR-amplified fragments flanked by NdeI and Xho I restriction enzyme sites into the pET28a vector (Novagen, Malaysia) described previously [33], as indicated in Table 1. Recombinant vectors were confirmed by using enzyme digestion and DNA 
sequencing (Sangon Biotech, Shanghai, China). Three site-directed VP2 mutants were obtained in vitro by using the Fast Site-Directed Mutagenesis Kit (Tiangen, Beijing, China). The pET28a plasmid, containing the full-length VP2 gene (1737 bp), was amplified by three pairs of mutation primers (Table 1). Briefly, amplification reactions were carried out in a total volume of $50 \mu \mathrm{L}$, containing $2 \mu \mathrm{L}$ of template DNA, $2 \mu \mathrm{L}$ of each forward and reverse primer $(10 \mu \mathrm{M}), 10 \mu \mathrm{L}$ of $5 \times$ Fast Alteration Buffer, $1 \mu \mathrm{L}$ of Fast Alteration DNA Polymerase $(1.0 \mathrm{U} / \mu \mathrm{L})$, and $33 \mu \mathrm{L}$ of RNAse-free water. Polymerase chain reaction (PCR) procedure was followed as described below. Initial denaturation was at 2 minutes at $95^{\circ} \mathrm{C}$ followed by $18 \mathrm{cycles}$, each cycle consisting of 20 seconds at $94^{\circ} \mathrm{C}, 10$ seconds at $55^{\circ} \mathrm{C}$ and 2.5 minute at $68^{\circ} \mathrm{C}$. The final extension was 5 minutes at $72^{\circ} \mathrm{C}$. After amplification, the PCR product was digested with $D p n$ I restriction enzyme at $37^{\circ} \mathrm{C}$ for 1 hour, and then $5 \mu \mathrm{L}$ of the digestion product was transformed into FDM competent cells to screen for mutants. Desired mutants were identified by DNA sequencing.

\section{Expression and purification of mutated VP2 protein}

Full-length and mutant VP2 proteins were expressed in the E. coli system. Cells were grown in LuriaBertani (LB) media supplemented with chloramphenicol $25 \mathrm{mg} / \mathrm{L}$, kanamycin $50 \mathrm{mg} / \mathrm{L}$, and L-Arabinose 2 $\mathrm{g} / \mathrm{L}$. Then isopropyl- $\beta$-D-thiogalactopyranoside (IPTG) was added at a final concentration of $0.15 \mathrm{mM}$ to induce recombinant protein expression. After culturing the cells for 12 hours at $25^{\circ} \mathrm{C}$ at $200 \mathrm{rpm}$, the cells were harvested by centrifugation, resuspended in buffer $\mathrm{A}(150 \mathrm{mM} \mathrm{NaCl}, 50 \mathrm{mM}$ Tris, $\mathrm{pH}$ 8.0), and lysed by ultrasonic treatment on ice. The expression of target recombinant protein was detected by western blotting (WB).

VP2 and mutant VP2 protein in the supernatant of E. coli cells were purified by a two-step method, using Ni-NTA affinity chromatography (Merck, Darmstadt, Germany) followed by SE-HPLC. Clarified cell lysates were pumped onto a Ni-NTA column balanced with 10 bed volumes of buffer A. After washing with 10 bed volumes of buffer $\mathrm{B}(150 \mathrm{mM} \mathrm{NaCl}, 50 \mathrm{mM}$ Tris, $25 \mathrm{mM}$ imidazole, $\mathrm{pH}$ 8.0), VP2 or mutant VP2 proteins were eluted with buffer $\mathrm{C}(150 \mathrm{mM} \mathrm{NaCl}, 50 \mathrm{mM}$ Tris, $150 \mathrm{mM}$ imidazole, $\mathrm{pH}$ 8.0). Fractions were further separated by SE-HPLC, using a Superdex ${ }^{\mathrm{TM}} 200$ 10/300 GL (GE Healthcare, Pittsburgh, PA, USA) column as described below. A Superdex ${ }^{\mathrm{TM}} 200$ 10/300 GL column was equilibrated with 10 bed volumes of buffer $A$ at a rate of $1 \mathrm{~mL} / \mathrm{min}$. Subsequently, samples were applied to the Superdex ${ }^{\mathrm{TM}} 20010 / 300 \mathrm{GL}$ column. After binding, fractions were further eluted with buffer A. Elution fractions were collected and determined by $12 \%(\mathrm{~V} / \mathrm{v})$ SDS-PAGE. Fractions containing VP2 protein or mutant VP2 proteins were filtered with a $0.22 \mu \mathrm{m}$ filter (Merck Millipore, Darmstadt, Germany) and quantified using a Micro BCA ${ }^{\text {TM }}$ protein assay kit (Solarbio, Beijing, China). Importantly, all purification procedures were carried out at $4^{\circ} \mathrm{C}$, and purified fractions were stored at $-80^{\circ} \mathrm{C}$ to retain biological activity.

\section{SDS-PAGE and western blotting analysis}

SDS-PAGE and western blotting were conducted to detect protein expression as described below. First, 5x loading buffer was added to each cell lysate or fraction. Then mixtures were heated at $100^{\circ} \mathrm{C}$ for 10 minutes, resolved by $12 \%$ SDS-PAGE, and finally stained with Coomassie blue (Beyotime, Shanghai, China). For WB, samples were transferred from SDS-PAGE to PVDF membranes (Bio-Rad, Richmond, 
California, USA). VP2 or mutant VP2 proteins were detected using a horseradish peroxidase (HRP)conjugated anti-his monoclonal antibody (Jackson ImmunoResearch, Philadelphia, PA, USA) at a dilution of 1:5,000. Membranes were observed with enhanced chemiluminescent reagent (NCM Biotech, Suzhou, China) or 3-amino-9-ethylcarbazole solution (ZSGB-BIO, Beijing, China), and examined by light microscopy (Leica DMI3000B) (Feica Microsystems, Wetzlar, Germany).

\section{HA analysis}

Supernatants containing VP2 or mutant VP2 were diluted with PBS for standard HA assays. To perform a HA test, $50 \mu \mathrm{L}$ of clarified cell lysates containing VP2 or mutant VP2 were 2 -fold diluted with PBS in a 96$\mathrm{V}$-shaped-well microtiter plate. Then $50 \mu \mathrm{L}$ of guinea pig erythrocytes $(0.8 \%)$ were added to each well. The plate was incubated at $37^{\circ} \mathrm{C}$ for 1 hour. HA titers were defined as the highest dilution that completely agglutinated guinea pig erythrocytes.

\section{Indirect enzyme-linked immunosorbent assay}

An indirect enzyme-linked immunosorbent assay was carried out using the conformational antibody $10 \mathrm{~A} 9$, which only recognizes assembled capsids, as prepared in our previous study. First, 96-well plates were coated with purified mutant VP2 proteins, wild-type VP2 protein, or DET 28a empty vector, and then blocked with $5 \%$ skim milk in PBST at $4^{\circ} \mathrm{C}$ at least 8 hours. The conformational antibody $10 \mathrm{~A} 9$ was used as the primary antibody and added into 96 -well plates at $37^{\circ} \mathrm{C}$ for 30 minutes. After washing with PBST for five times, an HRP-conjugated goat anti-mouse IgG antibody (Jackson ImmunoResearch, Philadelphia, PA, USA) was used as the secondary antibody and incubated in the plate at $37^{\circ} \mathrm{C}$ for 45 minutes. Finally, antibody binding was analyzed by adding TMB solution (Solarbio, Beijing, China), and 2 $\mathrm{M} \mathrm{H}_{2} \mathrm{SO}_{4}$ was added to stop the reaction. The optical density at $450 \mathrm{~nm}$ was recorded using a microplate reader (Omega Bio-Tek, Inc., Norcross, GA, Germany). All the experiments were performed in triplicate.

\section{Transmission electron microscopy analysis}

Transmission electron microscopy analysis was performed using a negative-staining method. Purified proteins were stained with $2 \%$ phosphotungstic acid (Solarbio, Beijing, China) for 1 minute and air-dried for 5 minutes at room temperature after removing excessive sample with filter paper. Grids were observed and imaged using a JEM-1400 (JEOL, Tokyo, Japan) at an acceleration voltage of $100 \mathrm{kV}$, with a magnification of $120,000 \times$.

\section{Dynamic light scattering assay}

A dynamic light scattering assay was measured at room temperature using the Nano Particle Analyzer (Malvern, Beijing, China). Samples were diluted to an identical concentration of $0.1 \mathrm{mg} / \mathrm{mL}$ before measurement, and all determinations were conducted at a scattering angle of $90^{\circ}$ and equilibrated to $25^{\circ} \mathrm{C}$. At least 20 acquisitions were collected for each sample. This assay was performed in triplicate for data analysis. 


\section{Sucrose gradient sedimentation analysis}

VP2 and mutant VP2 proteins were purified in sucrose gradients. A four-step gradient of $5 \%, 15 \%, 30 \%$, and $45 \%$ (wt/vol) sucrose was prepared in Tris-HCL buffer. All gradients were fractionated by bottom puncture, prepared in 12-mL tubes by loading $2 \mathrm{~mL} / \mathrm{step}$, and incubated at $4^{\circ} \mathrm{C}$ at least 8 hours to allow diffusion into a continuous gradient. Samples were firstly precipitated with $40 \%$ saturated ammonium sulfate (Sinopharm, Beijing, China), dialyzed with Tris-HCL buffer, loaded onto the gradients, and then ultracentrifuged at $200,000^{\prime} \mathrm{g}$ in a P40ST rotor at $4^{\circ} \mathrm{C}$ for 36 hours (Hitachi, Ibaraki, Japan). After ultracentrifugation, samples in each fraction were electrophoresed via SDS-PAGE and identified by WB as described above. Native morphology of these samples was further examined using the NativePAGE ${ }^{\text {TM }}$ Novex ${ }^{\circledR}$ Bis-Tris Gel System (Thermo Fisher Scientific, Waltham, MA, USA), and identified by LC-MSMS analysis (Sangon Biotech, Shanghai, China).

\section{Abbreviations}

Asn, N: Asparagine; DLS: dynamic light scattering assay; E. coli: Escherichia coli; ELISA: indirect enzymelinked immunosorbent assay; HA: hemagglutination; HRP: horseradish peroxidase; LC-MSMS: liquid chromatography-tandem mass spectrometry; Lys, K: lysine; MVM: minute virus of mice; PCR: polymerase chain reaction; PPV: porcine parvovirus; SE-HPLC: size-exclusion high-performance liquid chromatography; VP: Viral proteins; VLP: virus-like particles; WB: western blotting.

\section{Declarations}

\section{Ethics approval and consent to participate}

Not applicable.

\section{Consent for publication}

Not applicable.

\section{Availability of data and materials}

All data generated or analyzed during this study are included in this published article and its supplementary information files.

\section{Competing interests}

The authors declare that they have no competing interests.

\section{Funding}

This work was supported by grants from the National Key R\&D Program (2017YFD0501103) and "1125 talent gathering plan" of Zhengzhou, as well as the Special Fund for Scientific Research and Development 
of Henan Academy of Agricultural Sciences ([2017]76-21).

\section{Authors' contributions}

WJC, LYC, ZT, and CYM conceived of the experiments, WJC, LYC, WAP, WQ, LDM, and WFY performed the experiments, WJC, LYC and ZGP wrote the paper. All authors read and approved the final manuscript.

\section{Acknowledgements}

Not applicable.

\section{Authors' information}

a. Henan Provincial Key Laboratory of Animal Immunology, Henan Academy of Agricultural Sciences, Zhengzhou, 450002, China. b. College of Animal Science and Veterinary Medicine, Henan Agricultural University, Zhengzhou, 450002, China. c. School of Life Sciences, Zhengzhou University, Zhengzhou, 450001, China. d. Henan Zhongze Biological Engineering Co., Ltd, Zhengzhou, China. e. Jiangsu CoInnovation Center for the Prevention and Control of Important Animal Infectious Disease and Zoonose, Yangzhou University, Yangzhou, China

\section{References}

1. Oh WT, Kim RY, Nguyen VG, Chung HC, Park BK: Perspectives on the Evolution of Porcine Parvovirus. Viruses 2017, 9.

2. Song C, Zhu C, Zhang C, Cui S: Detection of porcine parvovirus using a taqman-based real-time pcr with primers and probe designed for the NS1 gene. Virol J 2010, 7:353.

3. Kaufmann B, Simpson AA, Rossmann MG: The structure of human parvovirus B19. Proc Natl Acad Sci U S A 2004, 101:11628-11633.

4. Meszaros I, Olasz F, Csagola A, Tijssen P, Zadori Z: Biology of Porcine Parvovirus (Ungulate parvovirus 1). Viruses 2017, 9.

5. Chandramouli S, Medina-Selby A, Coit D, Schaefer M, Spencer T, Brito LA, Zhang P, Otten G, Mandl CW, Mason PW, et al: Generation of a parvovirus B19 vaccine candidate. Vaccine 2013, 31:38723878.

6. Rueda P, Fominaya J, Langeveld JP, Bruschke C, Vela C, Casal JI: Effect of different baculovirus inactivation procedures on the integrity and immunogenicity of porcine parvovirus-like particles. Vaccine 2000, 19:726-734.

7. Tu M, Liu F, Chen S, Wang M, Cheng A: Role of capsid proteins in parvoviruses infection. Virol J 2015, 12:114.

8. Simpson AA, Hebert B, Sullivan GM, Parrish CR, Zadori Z, Tijssen P, Rossmann MG: The structure of porcine parvovirus: comparison with related viruses. J Mol Biol 2002, 315:1189-1198. 
9. Hafenstein S, Bowman VD, Sun T, Nelson CD, Palermo LM, Chipman PR, Battisti AJ, Parrish CR, Rossmann MG: Structural comparison of different antibodies interacting with parvovirus capsids. J Virol 2009, 83:5556-5566.

10. Yuan W, Parrish CR: Canine parvovirus capsid assembly and differences in mammalian and insect cells. Virology 2001, 279:546-557.

11. Hueffer K, Parrish CR: Parvovirus host range, cell tropism and evolution. Curr Opin Microbio/ 2003, 6:392-398.

12. Llamas-Saiz AL, Agbandje-McKenna M, Parker JS, Wahid AT, Parrish CR, Rossmann MG: Structural analysis of a mutation in canine parvovirus which controls antigenicity and host range. Virology 1996, 225:65-71.

13. Chang SF, Sgro JY, Parrish CR: Multiple amino acids in the capsid structure of canine parvovirus coordinately determine the canine host range and specific antigenic and hemagglutination properties. J Virol 1992, 66:6858-6867.

14. Agbandje-McKenna M, Llamas-Saiz AL, Wang F, Tattersall P, Rossmann MG: Functional implications of the structure of the murine parvovirus, minute virus of mice. Structure 1998, 6:1369-1381.

15. Antonis AF, Bruschke CJ, Rueda P, Maranga L, Casal JI, Vela C, Hilgers LA, Belt PB, Weerdmeester K, Carrondo MJ, Langeveld JP: A novel recombinant virus-like particle vaccine for prevention of porcine parvovirus-induced reproductive failure. Vaccine 2006, 24:5481-5490.

16. Organtini LJ, Lee H, Iketani S, Huang K, Ashley RE, Makhov AM, Conway JF, Parrish CR, Hafenstein S: Near-Atomic Resolution Structure of a Highly Neutralizing Fab Bound to Canine Parvovirus. J Virol 2016, 90:9733-9742.

17. Guo C, Zhong Z, Huang Y: Production and immunogenicity of VP2 protein of porcine parvovirus expressed in Pichia pastoris. Arch Virol 2014, 159:963-970.

18. Rymerson RT, Babiuk L, Menassa R, Vanderbeld B, Brandle JE: Immunogenicity of the capsid protein VP2 from porcine parvovirus expressed in low alkaloid transgenic tobacco. Molecular Breeding 2003, 11:267-276.

19. Ji P, Liu Y, Chen Y, Wang A, Jiang D, Zhao B, Wang J, Chai S, Zhou E, Zhang G: Porcine parvovirus capsid protein expressed in Escherichia coli self-assembles into virus-like particles with high immunogenicity in mice and guinea pigs. Antiviral Res 2017, 139:146-152.

20. Sanchez-Sanchez L, Tapia-Moreno A, Juarez-Moreno K, Patterson DP, Cadena-Nava RD, Douglas T, Vazquez-Duhalt R: Design of a VLP-nanovehicle for CYP450 enzymatic activity delivery. $J$ Nanobiotechnology 2015, 13:66.

21. Lino CA, Caldeira JC, Peabody DS: Display of single-chain variable fragments on bacteriophage MS2 virus-like particles. J Nanobiotechnology 2017, 15:13.

22. Li X, Meng X, Wang S, Li Z, Yang L, Tu L, Diao W, Yu C, Yu Y, Yan C, Wang L: Virus-like particles of recombinant PCV2b carrying FMDV-VP1 epitopes induce both anti-PCV and anti-FMDV antibody responses. App/ Microbiol Biotechnol 2018, 102:10541-10550. 
23. Crisci E, Barcena J, Montoya M: Virus-like particles: the new frontier of vaccines for animal viral infections. Vet Immunol Immunopathol 2012, 148:211-225.

24. Mohsen MO, Zha L, Cabral-Miranda G, Bachmann MF: Major findings and recent advances in viruslike particle (VLP)-based vaccines. Semin Immunol 2017, 34:123-132.

25. Carreira A, Menendez M, Reguera J, Almendral JM, Mateu MG: In vitro disassembly of a parvovirus capsid and effect on capsid stability of heterologous peptide insertions in surface loops. $\mathrm{J}$ Biol Chem 2004, 279:6517-6525.

26. Mateu MG: Assembly, stability and dynamics of virus capsids. Arch Biochem Biophys 2013, 531:6579.

27. Reguera J, Grueso E, Carreira A, Sanchez-Martinez C, Almendral JM, Mateu MG: Functional relevance of amino acid residues involved in interactions with ordered nucleic acid in a spherical virus. $J$ Biol Chem 2005, 280:17969-17977.

28. Riolobos L, Reguera J, Mateu MG, Almendral JM: Nuclear transport of trimeric assembly intermediates exerts a morphogenetic control on the icosahedral parvovirus capsid. J Mol Biol 2006, 357:1026-1038.

29. Perez R, Castellanos M, Rodriguez-Huete A, Mateu MG: Molecular determinants of self-association and rearrangement of a trimeric intermediate during the assembly of a parvovirus capsid. $\mathrm{J} \mathrm{Mol} \mathrm{Biol}$ 2011, 413:32-40.

30. Nelson LM, Rose RC, Moroianu J: Nuclear import strategies of high risk HPV16 L1 major capsid protein. J Biol Chem 2002, 277:23958-23964.

31. Reguera J, Carreira A, Riolobos L, Almendral JM, Mateu MG: Role of interfacial amino acid residues in assembly, stability, and conformation of a spherical virus capsid. Proc Natl Acad Sci U S A 2004, 101:2724-2729.

32. Bleker S, Sonntag F, Kleinschmidt JA: Mutational analysis of narrow pores at the fivefold symmetry axes of adeno-associated virus type 2 capsids reveals a dual role in genome packaging and activation of phospholipase A2 activity. J Virol 2005, 79:2528-2540.

33. Wang J, Liu Y, Chen Y, Wang A, Wei Q, Liu D, Zhang G: Large-scale manufacture of VP2 VLP vaccine against porcine parvovirus in Escherichia coli with high-density fermentation. App/ Microbiol Biotechnol 2020, 104:3847-3857.

34. Chevalier C, Lepault J, Da Costa B, Delmas B: The last C-terminal residue of VP3, glutamic acid 257, controls capsid assembly of infectious bursal disease virus. J Viro/ 2004, 78:3296-3303.

35. Mo X, Li X, Yin B, Deng J, Tian K, Yuan A: Structural roles of PCV2 capsid protein N-terminus in PCV2 particle assembly and identification of PCV2 type-specific neutralizing epitope. PLoS Pathog 2019, 15:e1007562.

36. Li TC, Takeda N, Miyamura T, Matsuura Y, Wang JC, Engvall H, Hammar L, Xing L, Cheng RH: Essential elements of the capsid protein for self-assembly into empty virus-like particles of hepatitis E virus. J Virol 2005, 79:12999-13006. 
37. Sanchez-Rodriguez SP, Munch-Anguiano L, Echeverria O, Vazquez-Nin G, Mora-Pale M, Dordick JS, Bustos-Jaimes I: Human parvovirus B19 virus-like particles: In vitro assembly and stability. Biochimie 2012, 94:870-878.

38. Mateo R, Diaz A, Baranowski E, Mateu MG: Complete alanine scanning of intersubunit interfaces in a foot-and-mouth disease virus capsid reveals critical contributions of many side chains to particle stability and viral function. J Biol Chem 2003, 278:41019-41027.

39. Cotmore SF, Tattersall P: Mutations at the base of the icosahedral five-fold cylinders of minute virus of mice induce 3'-to-5' genome uncoating and critically impair entry functions. $J$ Viro/ 2012, 86:69-80.

40. Joshi A, Nagashima K, Freed EO: Mutation of dileucine-like motifs in the human immunodeficiency virus type 1 capsid disrupts virus assembly, gag-gag interactions, gag-membrane binding, and virion maturation. J Virol 2006, 80:7939-7951.

41. Moyer CL, Besser ES, Nemerow GR: A Single Maturation Cleavage Site in Adenovirus Impacts Cell Entry and Capsid Assembly. J Virol 2016, 90:521-532.

\section{Tables}


Table 1

Primers Used for Construction of N-terminal Deletion or Site-directed Mutants of VP2 Protein

\begin{tabular}{|c|c|c|c|}
\hline Number & Name & Sequence $\left(5^{\prime}-3^{\prime}\right)$ & Residues sites \\
\hline \multirow[t]{2}{*}{1} & NT $\Delta 100 a a-F$ & ggaattccatatggcgcatacccaaatggt & \multirow[t]{2}{*}{ 101-579aа } \\
\hline & NT $\Delta 100 a a-R$ & ccgctcgagttaatacagtttccgtggaatgag & \\
\hline \multirow[t]{2}{*}{2} & NT $\Delta 50$ aa-F & ggaattccatatggaatttcagtatctgggcgaag & \multirow[t]{2}{*}{ 51-579aa } \\
\hline & NT $\Delta 50 a a-R$ & ccgctcgagttaatacagtttccgtggaatgag & \\
\hline \multirow[t]{2}{*}{3} & NT $\Delta 49 a a-F$ & ggaattccatatgaccgaatttcagtatctggg & \multirow[t]{2}{*}{$50-579 a a$} \\
\hline & NT $\Delta 49 a a-R$ & ccgctcgagttaatacagtttccgtggaatgag & \\
\hline \multirow[t]{2}{*}{4} & NT $\Delta 48 \mathrm{aa}-\mathrm{F}$ & ggaattccatatgcagaccgaatttcagtatctgg & \multirow[t]{2}{*}{ 49-579aa } \\
\hline & NT $\Delta 48 \mathrm{aa}-\mathrm{R}$ & ccgctcgagttaatacagtttccgtggaatgag & \\
\hline \multirow[t]{2}{*}{5} & NT $\Delta 47 a a-F$ & ggaattccatatgaatcagaccgaatttcagtatctg & \multirow[t]{2}{*}{ 48-579aa } \\
\hline & NT $\Delta 47 a a-R$ & ccgctcgagttaatacagtttccgtggaatgag & \\
\hline \multirow[t]{2}{*}{6} & NT $\Delta 46 a a-F$ & ggaattccatatgaacaatcagaccgaatttcagtat & \multirow[t]{2}{*}{ 47-579aa } \\
\hline & NT $\Delta 46 a a-R$ & ccgctcgagttaatacagtttccgtggaatgag & \\
\hline \multirow[t]{2}{*}{7} & NT $\Delta 45 \mathrm{aa}-\mathrm{F}$ & ggaattccatatgtttaacaatcagaccgaatttcagt & \multirow[t]{2}{*}{ 46-579aa } \\
\hline & NT $\Delta 45 \mathrm{aa}-\mathrm{R}$ & ccgctcgagttaatacagtttccgtggaatgag & \\
\hline \multirow[t]{2}{*}{8} & NT $\Delta 40 \mathrm{aa}-\mathrm{F}$ & ggaattccatatggtgtctacgggtacctttaaca & \multirow[t]{2}{*}{ 41-579aa } \\
\hline & NT $\Delta 40 \mathrm{aa}-\mathrm{R}$ & ccgctcgagttaatacagtttccgtggaatgag & \\
\hline \multirow[t]{2}{*}{9} & NT $\Delta 35 \mathrm{aa}-\mathrm{F}$ & ggaattccatatggcaggcggcgttg & \multirow[t]{2}{*}{ 36-579aa } \\
\hline & NT $\Delta 35 \mathrm{a} a-\mathrm{R}$ & ccgctcgagttaatacagtttccgtggaatgag & \\
\hline \multirow[t]{2}{*}{10} & NT $\Delta 30 a a-F$ & ggaattccatatgggtggcgggcgc & \multirow[t]{2}{*}{ 31-579aa } \\
\hline & NT $\Delta 30 a a-R$ & ccgctcgagttaatacagtttccgtggaatgag & \\
\hline \multirow[t]{2}{*}{11} & N47K-F & tgtctacgggtacctttaaaaatcagaccga & \multirow[t]{2}{*}{ 47aa } \\
\hline & N47K-R & tttaaaggtacccgtagacacgccaacgc & \\
\hline \multirow[t]{2}{*}{12} & N48K-F & ctacgggtacctttaacaaacagaccgaat & \multirow[t]{2}{*}{ 48aa } \\
\hline & N48K-R & tttgttaaaggtacccgtagacacgccaac & \\
\hline \multirow[t]{2}{*}{13} & N47KN48K-F & tctacgggtacctttaaaaaacagaccgaatttcagtatc & \multirow[t]{2}{*}{ 47-48aa } \\
\hline & N47KN48K-R & gatactgaaattcggtctgttttttaaaggtacccgtaga & \\
\hline
\end{tabular}




\begin{tabular}{|l|l|}
\hline Name & HA Titers \\
\hline VP2-full & $2^{16}$ \\
\hline NT- $\Delta$ 100aal None \\
\hline NT- $\Delta$ 50aa & None \\
\hline NT- $\Delta 49$ aa & None \\
\hline NT- $\Delta 48$ aa & None \\
\hline NT- $\Delta 47$ aa & $2^{10}$ \\
\hline NT- $\Delta 46$ aa & $2^{16}$ \\
\hline NT- $\Delta 45$ aa & $2^{15}$ \\
\hline NT- $\Delta 40$ aa & $2^{16}$ \\
\hline NT- $\Delta 35$ aa & $2^{16}$ \\
\hline NT- $\Delta 30$ aa & $2^{16}$ \\
\hline N47K & $2^{14}$ \\
\hline N48K & None \\
\hline N47KN48K & None \\
\hline
\end{tabular}

Table 3. Characteristics of Mutated VP2 Proteins

\section{Figures}

\begin{tabular}{|c|c|c|c|c|}
\hline Name & HA Tit & $\begin{array}{l}\text { SSE-HPLC } \\
\text { Time (min }\end{array}$ & \begin{tabular}{l|l|l} 
DLS & TEM \\
Size $(\mathrm{nm})$ & Size $(\mathrm{nm}$ \\
\end{tabular} & $\begin{array}{l}\text { ELISA } \\
\text { titers } \\
\end{array}$ \\
\hline VP2-full & $2^{16}$ & 8.5 & $25,25,25 \sim 25 \mathrm{~nm}$ & $1: 1280,000$ \\
\hline NT- $\Delta 30$ aa & $2^{16}$ & 8.4 & $24,24,25 \sim 25 \mathrm{~nm}$ & $1: 1280,000$ \\
\hline NT- $\Delta 47 \mathrm{aa}$ & $2^{10}$ & 8.6 & $25,25,26 \sim 25 \mathrm{~nm}$ & $1: 1280,000$ \\
\hline NT- $\Delta 48 \mathrm{aa}$ & None & 7.3 & $32,45,30$ None & None \\
\hline N47K & $2^{14}$ & 8.4 & $23,24,25 \sim 25 \mathrm{~nm}$ & $1: 640,000$ (peak1) \\
\hline N48K & None & 7.5 & $20,37,45$ None & None \\
\hline
\end{tabular}

VP2

N-terminus

NT $\Delta 30 a a$

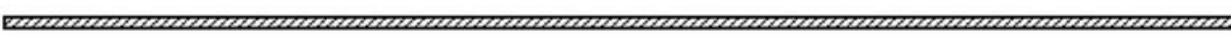

NT $\Delta 47 \mathbf{a a}$

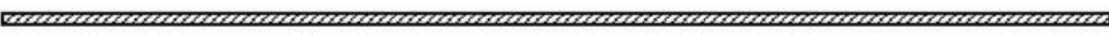

NT $\Delta 100 a a$

00000000000000000000000000000000000000000000000000000000000000000000000000

N47K

$\mathbf{K}$

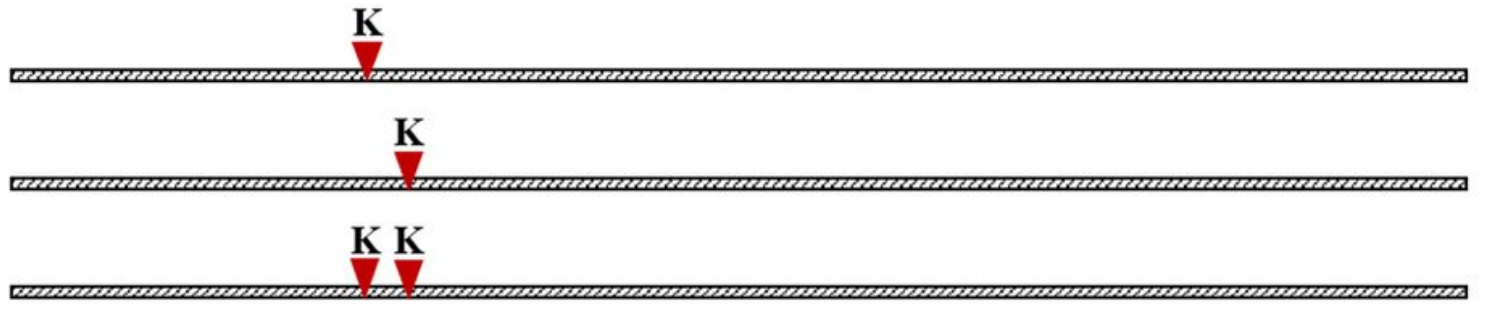

Figure 1 
Diagrams of deletion mutants and site-directed mutants of VP2 protein. Ten deletion mutants (only shown three) and three site-directed mutants were constructed. Three N-terminal deletion mutants, with 30,47 , and 100 amino acid residues of the VP2 protein removed, namely NT- $\Delta 30$ aa, NT- $\Delta 50$ aa, NT$\triangle 100 \mathrm{aa}$, were constructed and expressed in E. coli. Three site-directed mutants were designed and constructed by replacing 47Asn $(\mathrm{N})$ and/or 48Asn $(\mathrm{N})$ with a lysine (Lys, K) in the full-length VP2 protein.

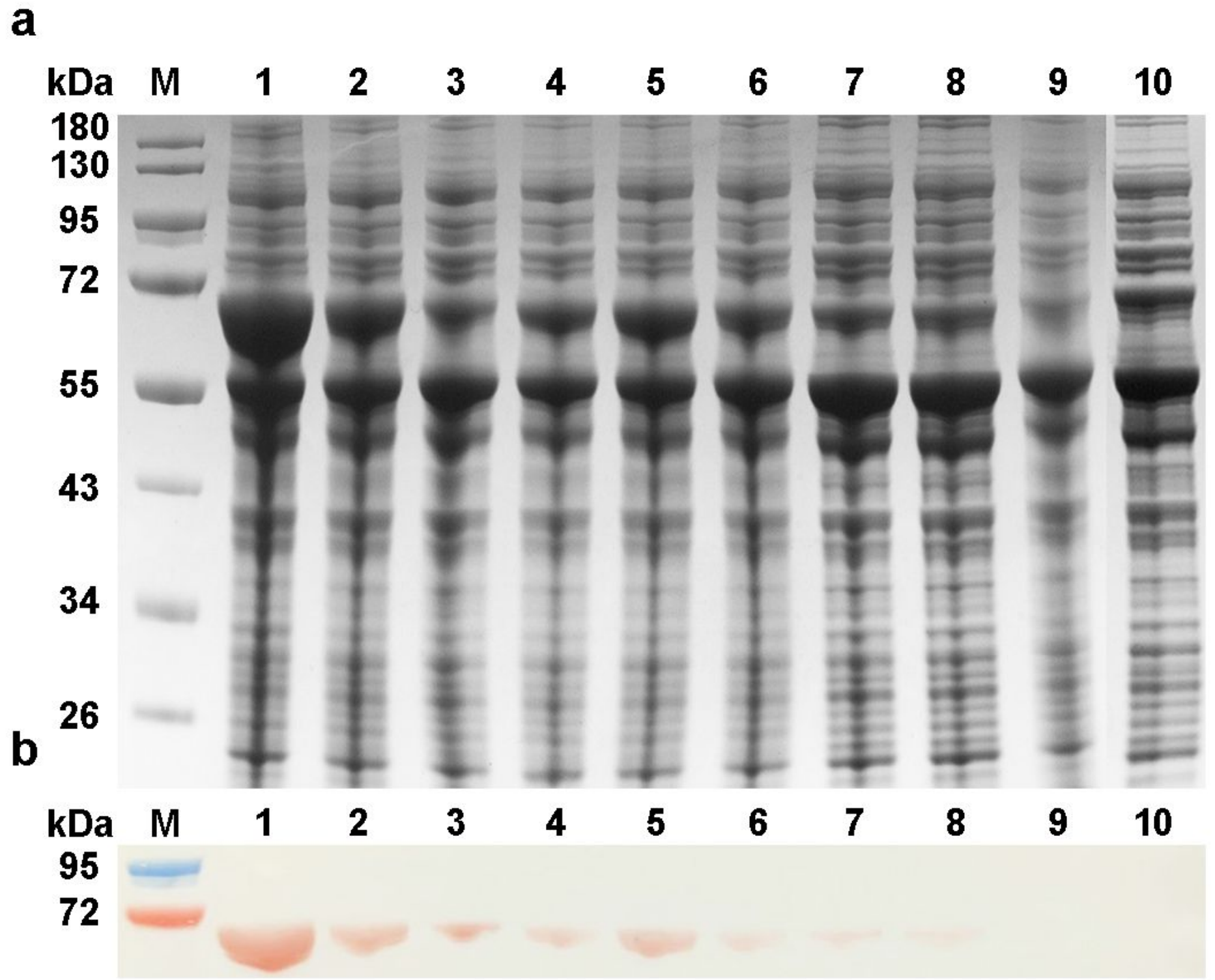

Figure 2

Expression and identification of mutants with deletions in the N-terminal region of the VP2 protein by SDS-PAGE and western blotting. a SDS-PAGE analysis of mutated VP2 proteins. b Western blotting analysis of mutated VP2 proteins with an anti-His monoclonal antibody. M, Marker; 1, NT- $\Delta 30 a a ; 2$, NT-

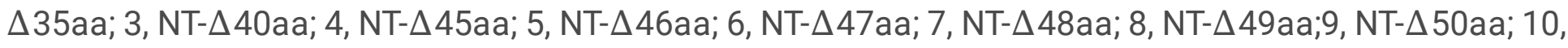
NT- $\Delta 100$ aa. 

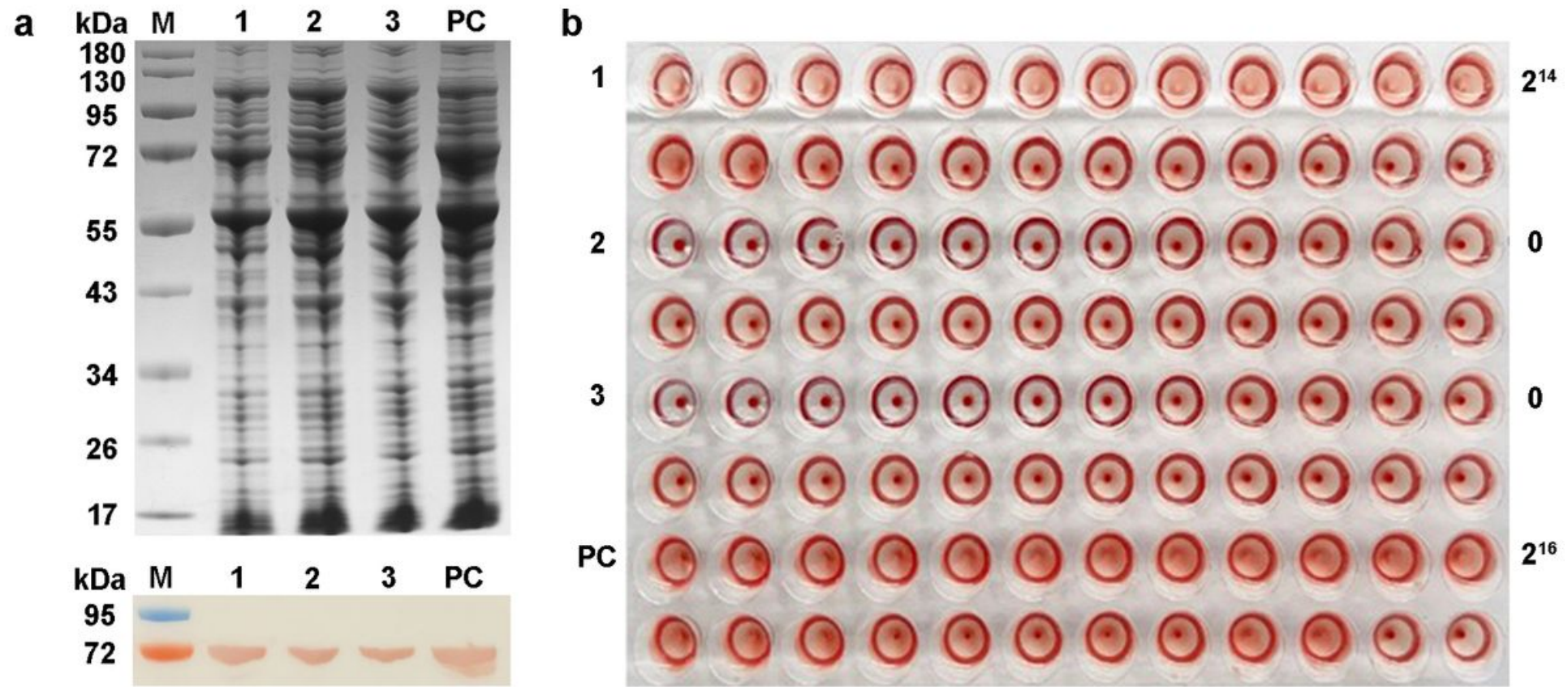

\section{Figure 3}

Identification of site-directed mutants of the VP2 protein. a Expression and identification of site-directed mutants of the VP2 protein by SDS-PAGE and western blotting. M, Marker;1, N47K; 2, N48K; 3, N47KN48K; PC, full-length VP2 protein. b HA results for site-directed mutants of VP2 protein. 1, N47K; 2, N48K; 3 , N47KN48K; PC, full-length VP2 protein. 

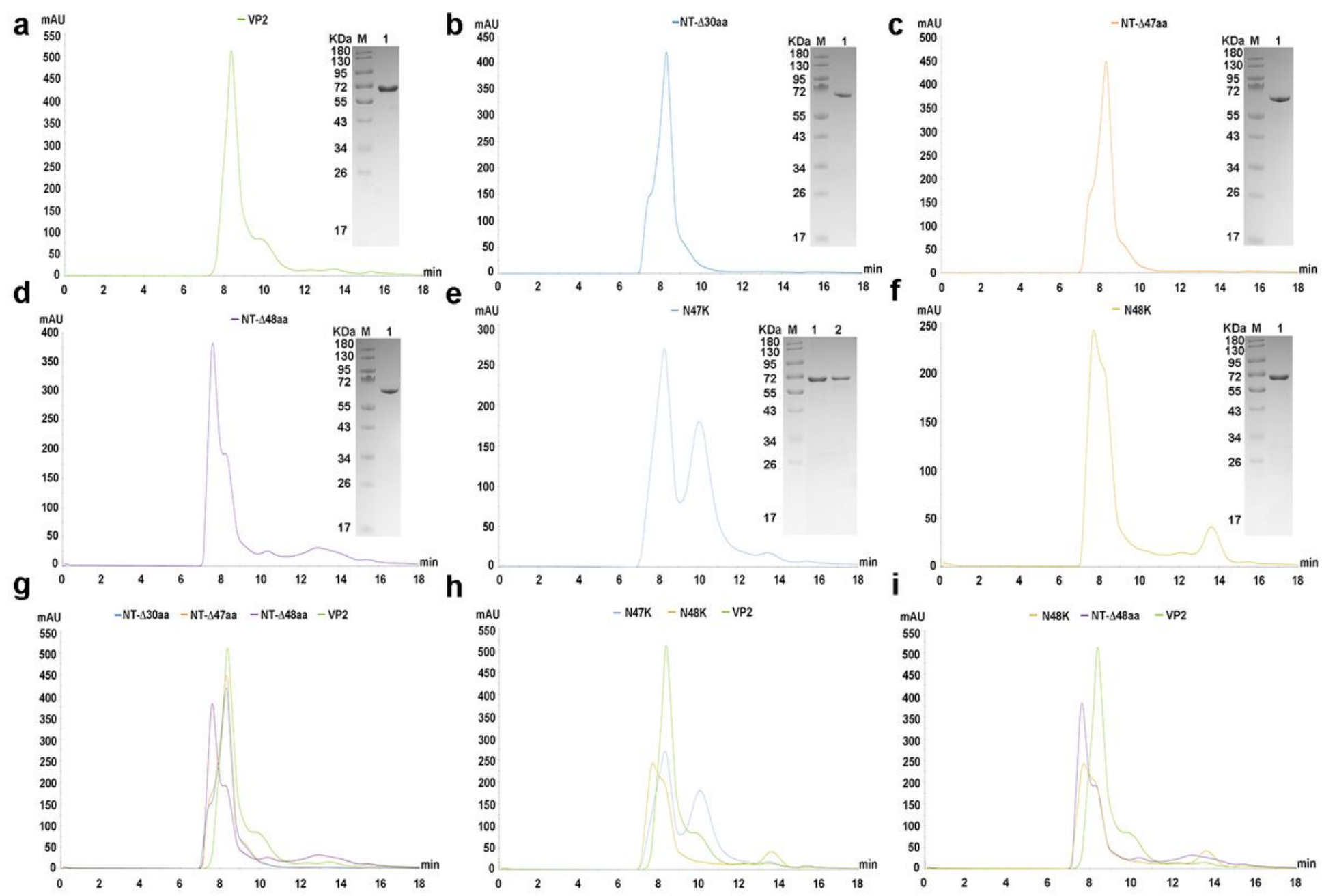

Figure 4

Protein purification results of PPV VP2 protein and mutant VP2 proteins. The purity of VP2 protein or mutant VP2 proteins was more than $90 \%$. Eluted fractions from a Ni-NTA column were further evaluated by SE-HPLC analysis, using a Superdex ${ }^{\mathrm{TM}} 20010 / 300$ GL column. In the chromatogram, the $y$-axis indicates the absorbance ( $280 \mathrm{~nm}, \mathrm{mAU})$, while the $\mathrm{x}$-axis indicates elution time (min). a VP2; $b$ NT$\Delta 30$ aa; c NT- $\Delta 47 \mathrm{aa}$; d NT- $\Delta 48 \mathrm{aa}$; e N47K; f N48K; g results compared between NT- $\Delta 30 \mathrm{aa}$, NT- $\Delta 47 \mathrm{aa}$, and NT- $\triangle 48$ aa with full-length VP2; $\mathrm{h}$ results compared between N47K and N48K with full-length VP2 protein; $\mathrm{i}$ results compared between N48K and NT- $\Delta 48$ aa with full-length VP2. 


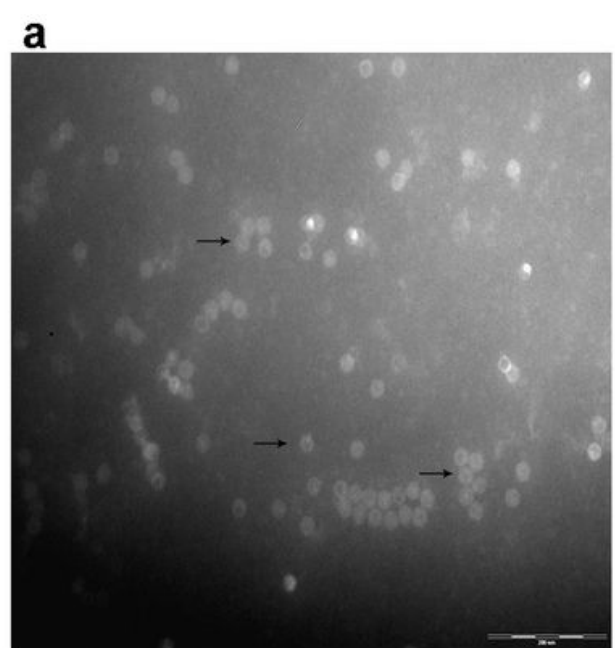

d

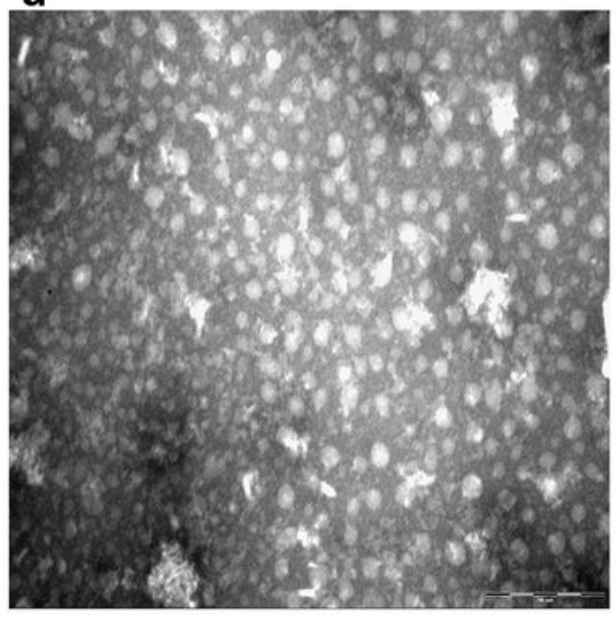

b

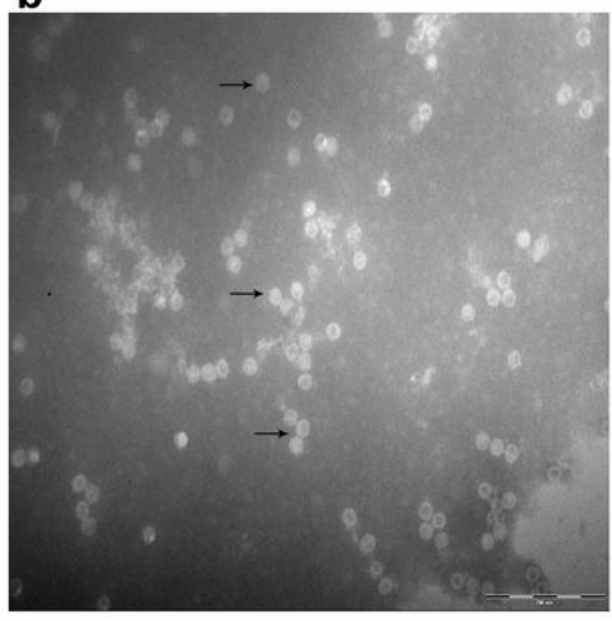

e

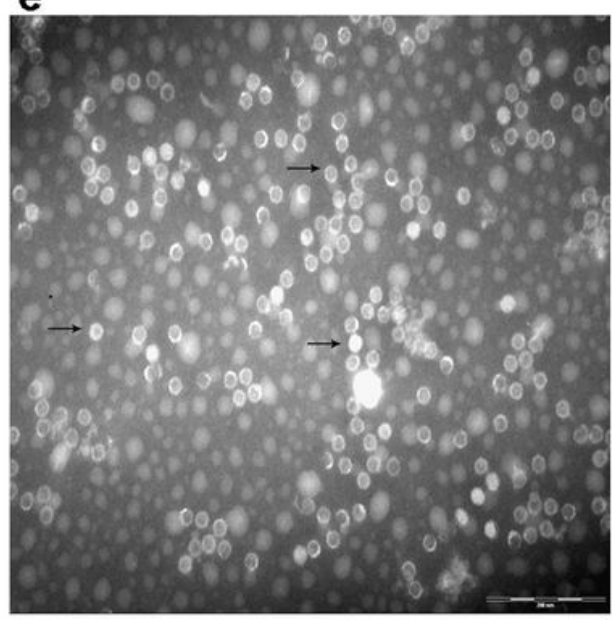

C

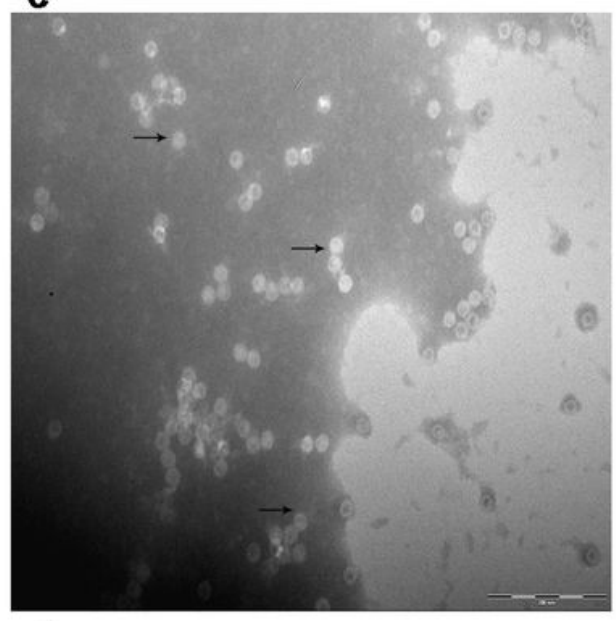

f

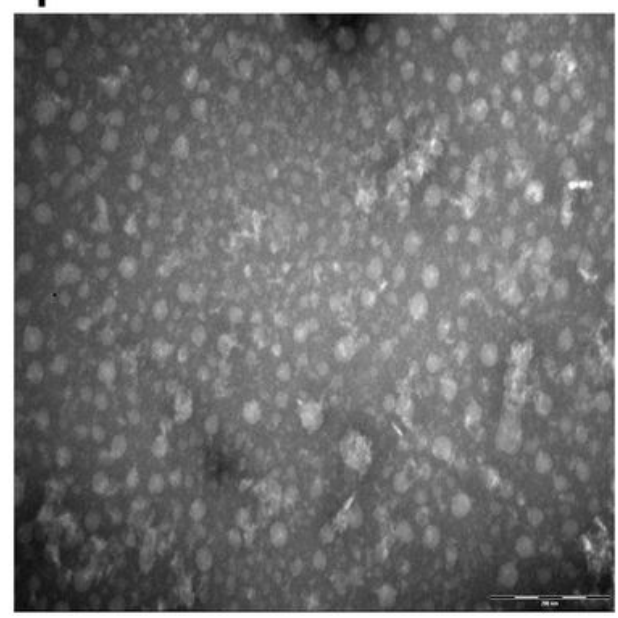

\section{Figure 5}

Transmission electron microscopy results of purified mutant VP2 proteins. a VP2; b NT- $\Delta 30$ aa; c NT$\Delta 47 \mathrm{aa} ; \mathrm{d}$ NT- $\Delta 48 \mathrm{aa} ; \mathrm{e}$ N47K; f N48K. The bar was $200 \mathrm{~nm}$, and VLP are indicated with arrows. 


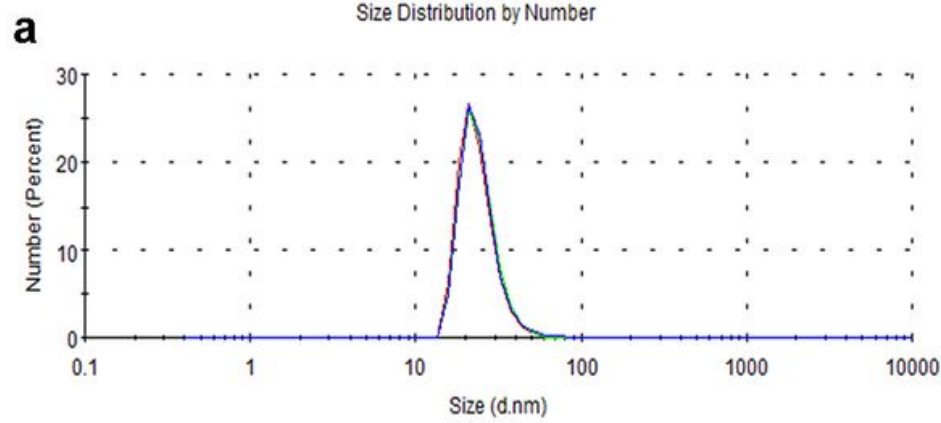

C

Size Distribution by Number

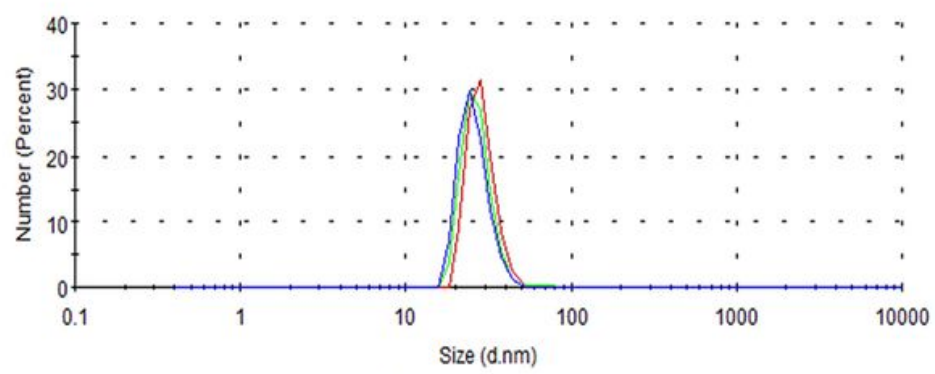

e

Size Distribution by Number

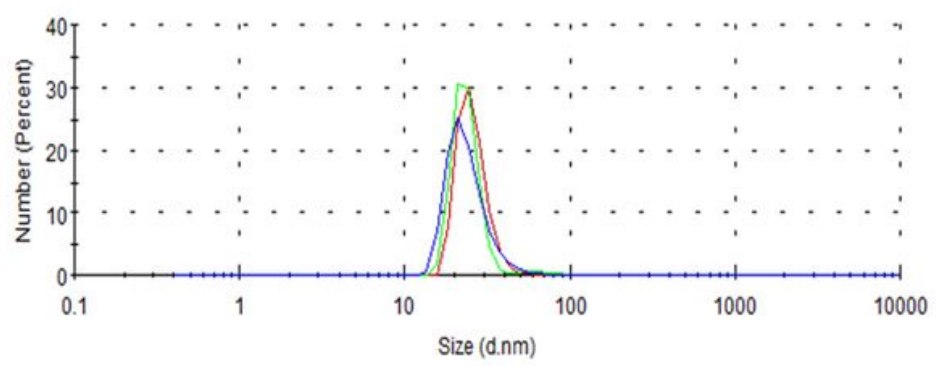

b

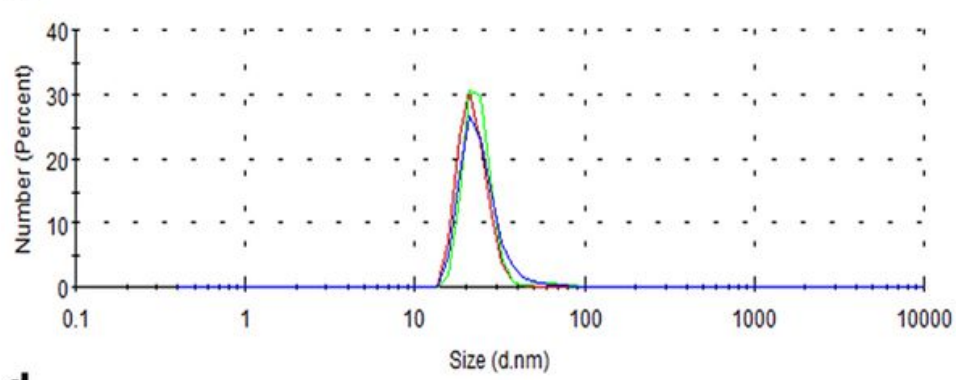

d

Size Distribution by Number

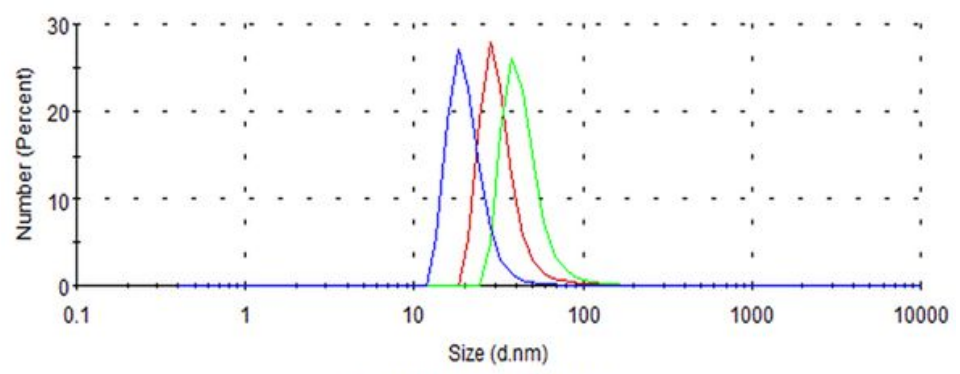

Size Distribution by Number

f

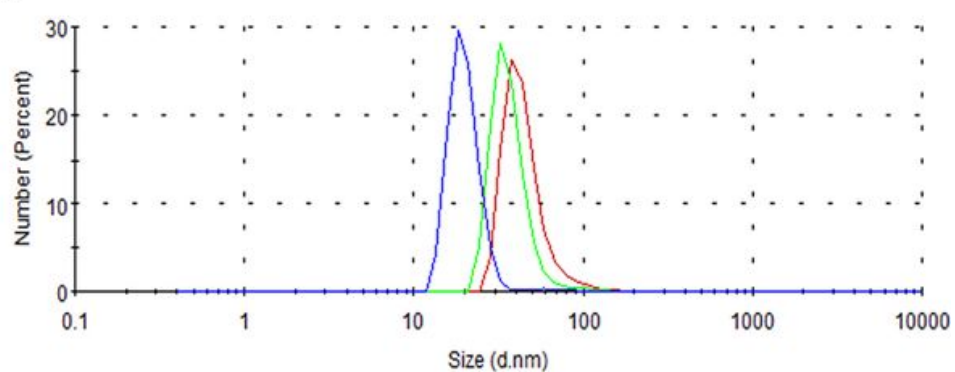

Figure 6

Dynamic light scattering results of mutant VP2 proteins. a VP2; b NT- $\Delta 30$ aa; c NT- $\Delta 47 a a ; d$ NT- $\Delta 48 a a ; e$ N47K; f N48K. At least 20 acquisitions were collected from each sample. Each sample was performed in triplicate for data analysis. 
a

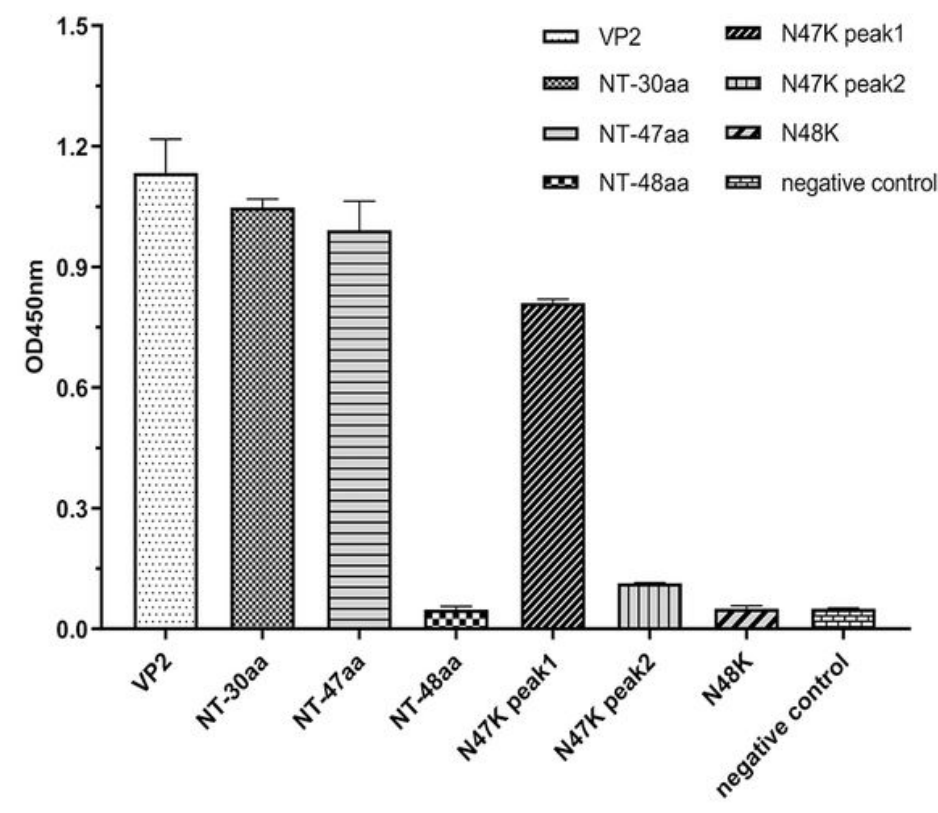

b

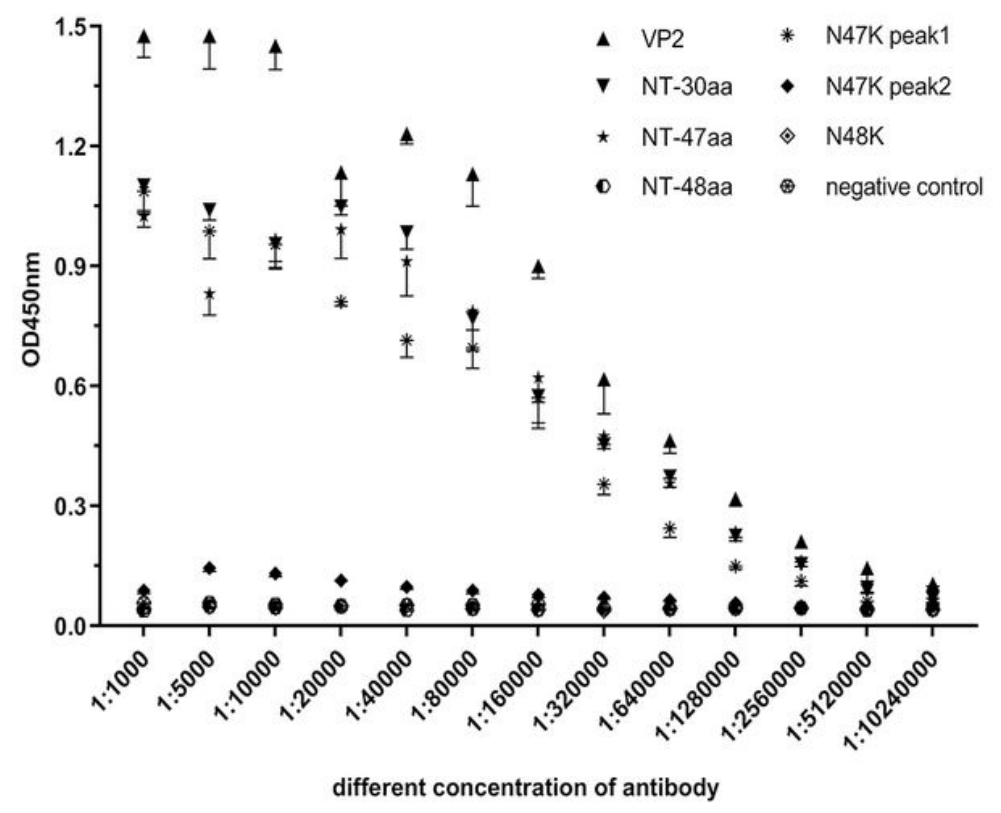

\section{Figure 7}

Binding characteristics of purified mutant VP2 proteins using the conformational antibody 10A9. a ELISA results for mutant VP2 proteins using the antibody $10 \mathrm{~A} 9$ at a certain concentration. Antibody 10A9 was diluted 1:20,000. b Antibody titers of mutant VP2 proteins using the antibody $10 \mathrm{~A}$. 
Franction:5\% 45\% sucrose gradient

a top

bottom

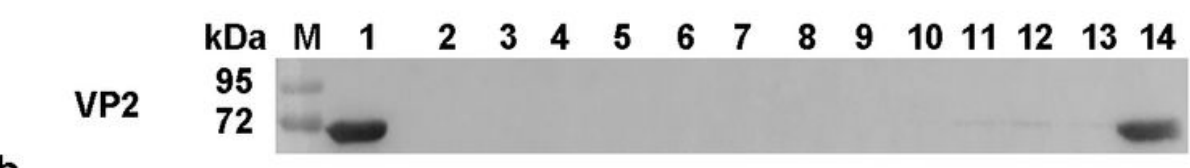

b

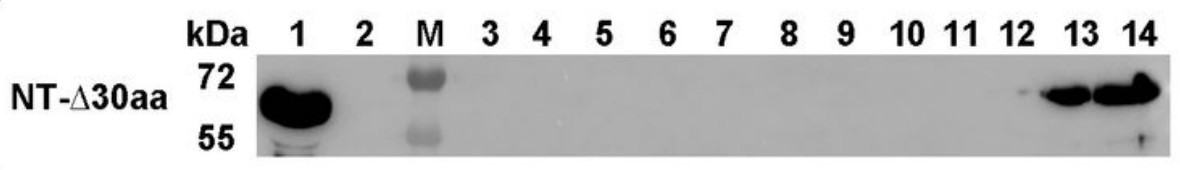

C

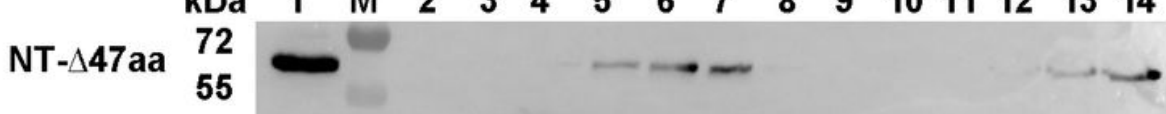

d

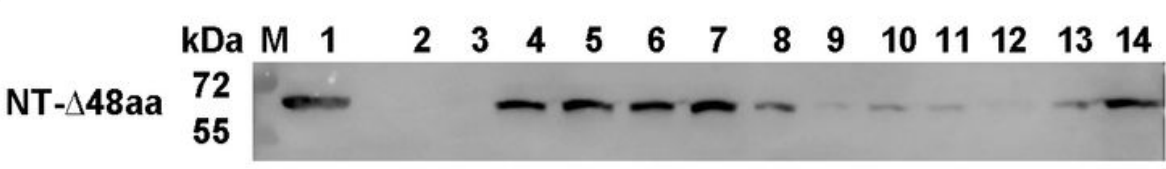

e

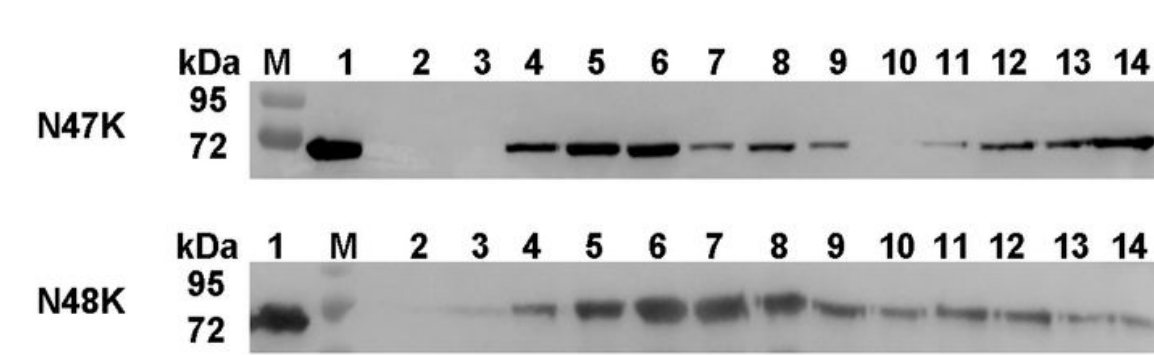

\section{Figure 8}

Sucrose gradients results of VP2 and mutant VP2 proteins. Supernatants of E. coli cells expressing VP2 or mutant VP2 proteins were sedimented by $40 \%$ saturated ammonium sulfate, dialyzed, and then separated through sucrose gradients. Figures are representative of western blotting analysis of fractions from different sucrose gradients. $M$, Marker; 1 , sedimented sample; 2-3, fractions from sample layer; 46 , fractions from $5 \%$ sucrose layer; $7-9$, fractions from $15 \%$ sucrose layer; $10-12$, fractions from $30 \%$ sucrose layer; $13-14$, fractions from $45 \%$ sucrose layer. a VP2; b NT- $\Delta 30$ aa; c NT- $\Delta 47$ aa; d NT- $\Delta 48 a a ; e$ N47K; f N48K. 
a

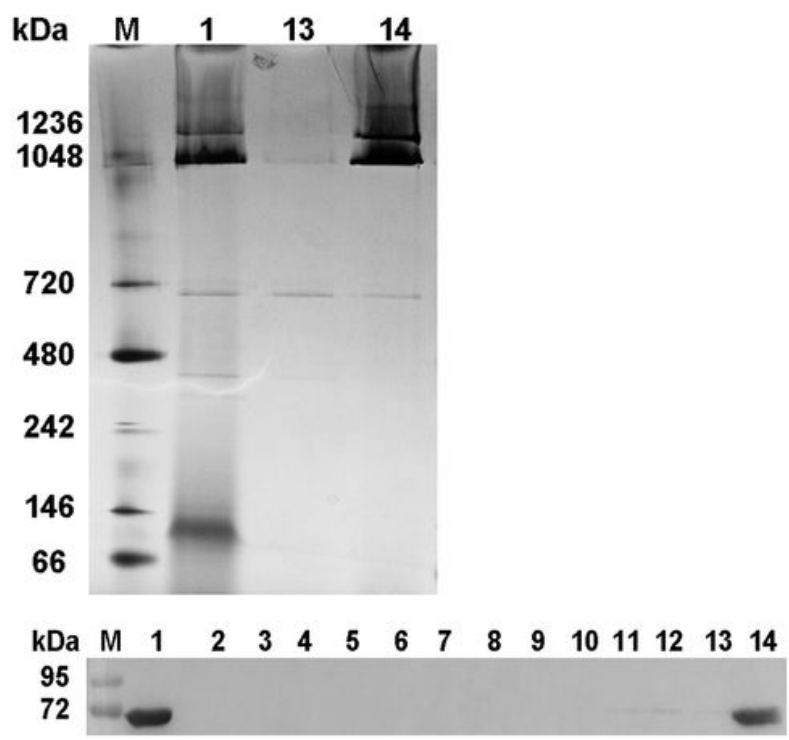

b

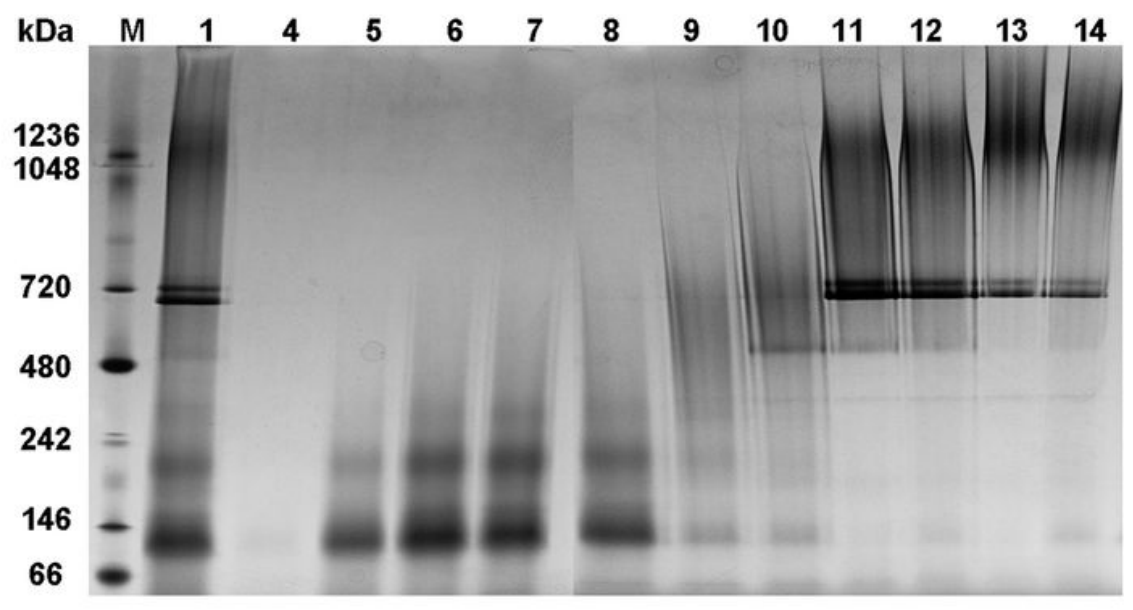

kDa

72

\section{Figure 9}

Analysis of the different protein subunits of the VP2 and N48K proteins by Native PAGE. Samples were purified by sucrose gradient sedimentation, and the results were consistent with those shown by western blotting analysis. M, Native Marker; 1, sedimented sample; 2-3, fractions from sample layer; 4-6, fractions from $5 \%$ sucrose layer; $7-9$, fractions from $15 \%$ sucrose layer; $10-12$, fractions from $30 \%$ sucrose layer; $13-14$, fractions from $45 \%$ sucrose layer. a VP2; b N48K

\section{Supplementary Files}

This is a list of supplementary files associated with this preprint. Click to download.

- Graphicalabstract.tif

- Additionalfiles.docx

- Figures11.tif

- FigureS12.tif 